\title{
EL ARREGLO DE LAS CONTROVERSIAS TERRITORIALES POR LA CORTE INTERNACIONAL DE JUSTICIA. UNA APROXIMACIÓN A SUS LÍNEAS DIRECTRICES.
}

\author{
Ana Gemma LÓPEZ MARTíN \\ PROFESORA TITULAR DE DERECHO INTERNACIONAL PÚBLICO \\ UNIVERSIDAD COMPLUTENSE DE MADRID \\ MIEMBRO DEL IHLADI
}

SUMARIO: I. La importancia de las controversias territoriales en la jurisprudencia de la Corte Internacional de Justicia. II. La irrelevancia de la distinción entre conflictos de delimitación y conflictos de adquisición. III. Los modos de atribución del título de soberanía territorial derivados de una situación de hecho. IV. La consolidación de los principales títulos jurídicos: uti possidetis iuris y principio de continuidad de los tratados de fronteras. V. La interacción entre los títulos jurídicos y la posesión efectiva. VI. Las efectividades y el principio de relatividad de la posesión efectiva. VII. La conducta recíproca de las partes. VIII. Una importante institución procesal: la fecha crítica. IX. Una reflexión final.

RESUMEN: La labor de la Corte Internacional de Justicia en el arreglo de las controversias territoriales ha sido y es sumamente prolífera. Su vasta jurisprudencia en este ámbito ha generado toda una serie de principios y reglas sobre las cuales se sustenta dicho arreglo, tales como el principio de continuidad de los tratados de carácter territorial, el uti possidetis iuris, la primacía del título jurídico, la relatividad de la efectividad, o la fecha crítica. Principios y reglas cuyo conocimiento es fundamental, no sólo para los tribunales internacionales, sino para aquellos Estados inmersos en una controversia territorial.

PALABRAS ClAVE: Corte Internacional de Justicia, controversias territoriales, título jurídico, posesión efectiva.

ABSTRACT: The work of the International Court of Justice in the settlement of territorial disputes has been and is extremely prolific. His extensive jurisprudence in this area has generated a number of principles and rules on which is based this arrangement, such as the principle of continuity of territorial treaties, the principle of uti possidetis iuris, the primacy of legal title, the relativity of the effectiveness, or the critical date. This principles and rules are essential not only to International Courts, but for those States engaged in a territorial dispute.

KEYWORDS: International Court of Justice, territorial disputes, legal title, effective possession. 


\section{La importancia de las controversias territoriales en la jurisprudencia de la Corte Internacional de Justicia}

Es más que evidente que las controversias territoriales no son rémoras del pasado sino una realidad de la más candente actualidad, como lo demuestran los, aproximadamente, cuarenta y cinco conflictos territoriales ${ }^{\mathrm{I}}$ que están aún pendientes de solución repartidos por los cinco continentes que, sin desembocar siempre en una confrontación bélica, sí suponen una fricción permanente. Si bien es cierto que no todos ellos se encuentran abiertos con la misma intensidad, motivo por el cual no trascienden de igual forma a la opinión pública. Resulta así que junto a controversias candentes y palpitantes (como las relativas a las Islas Senkaku, las Islas Spratley, las Islas Tokdo, o la más reciente disputa fronteriza entre Sudán y Sudán Sur), existen otras que se hallan en lo que podríamos denominar «estado latente», es decir, la disputa se planteó en su momento, no ha sido resuelta, de forma tal que los Estados implicados no dan por zanjado el conflicto, sino que se reservan el derecho a reabrir la controversia en cualquier momento (como la relativa a las Islas de los Monjes, al área de las Cataratas de Guaira y del río Parena, o la frontera entre Arabia Saudí y Yemen).

Pero, sin duda, el aspecto más interesante a retener en el contexto de los contenciosos territoriales viene referido a la solución pacífica de los mismos, de tal forma que podemos referir más de cien controversias territoriales ya resueltas, tanto por medios no jurisdiccionales, como jurisdiccionales. Setenta son las disputas territoriales resueltas por la vía jurisdiccional, esto es, han supuesto una decisión vinculante para las partes y, por tanto, la resolución definitiva de la disputa. Y es que una de las materias de Derecho internacional más habitual en la jurisprudencia internacional es sin duda la relativa a las controversias territoriales, esto es, la disputa entre dos Estados por la soberanía sobre una porción de superficie terrestre y la consiguiente determinación del título de los mismos sobre dicha parte física. Siendo especialmente reseñable a este respecto, la jurisprudencia de la Corte Internacional de Justicia (en adelante CIJ) ${ }^{2}$, pues, no en vano, ésta constituye la piedra angular de todo sistema de arreglo de controversias entre Estados; siendo, de hecho, el medio institucional de arreglo judicial más importante que la comunidad internacional tiene a su disposición.

Resulta así que, desde el inicial asunto de Minquiers y Ecrehous resuelto en I953 hasta la sentencia de 16 de abril de 2013 solucionando la controversia fronteriza entre Burkina Faso y Níger, la Corte mundial ha emitido un total de dieciocho sentencias cuyo objeto principal era una controversia territorial, esto es, una disputa sobre la soberanía de un territorio determinado. A saber': 29 de enero de 1953 (Minquiers y Ecrehous -

\footnotetext{
${ }^{1}$ Una exposición de todas estas disputas territoriales pendientes puede verse en LÓPEZ MARTín, A.G., «Clásico pero actual: el territorio estatal», Anuario Hispano Luso Americano de Derecho Internacional, vol. XVII, 2005, pp.173-206.

${ }^{2}$ Situados en el ámbito del arreglo arbitral, contamos con cincuenta y cuatro laudos que han resuelto otras tantas controversias territoriales. El primer arbitraje fue el relativo al Río St. Croix (Reino Unido/EEUU), sentencia de 25 de octubre de I798; y el último laudo arbitral en la materia fue dictado el I3 de abril de 2002 en el asunto sobre la delimitación de la frontera entre Eritrea y Etiopía.

${ }^{3}$ Toda la jurisprudencia de la CIJ referida en el presente trabajo puede consultarse en la página Web de la Corte: http://www.icj-cij.org/docket/index.php?pI=3\&p2=2 (fecha de consulta 13.5.2013).

Asimismo, los asuntos más recientes de la CIJ han sido objeto de comentario en la obra colectiva SÁNCHEZ RodrígueZ, L.I., Quel López, F.J., Y López MARTín, A.G. (eds.), El poder de los jueces y el estado actual del Derecho
} 
Francia/Reino Unido-); 20 de junio de I959 (Soberanía sobre ciertas parcelas fronterizas Bélgica/Países Bajos-); I8 de noviembre de I960 (Laudo arbitral del Rey de España de 23 diciembre 1906 -Honduras c. Nicaragua-); i5 de junio de I962 (Templo de Préah Vihéar Camboya c. Tailandia-); 22 de diciembre de 1986 (Controversia fronteriza -Burkina Faso/Mali-); II de septiembre de 1992 (Controversia fronteriza terrestre, insular y marítima El Salvador/Honduras; Nicaragua interviniente-); 3 de febrero de 1994 (Controversia territorial -Jamahiriya árabe libia/ Chad-); I3 de diciembre deı999 (Isla de Kasikili/Sedudu Botswana y Namibia-); i6 de marzo de 200 I (Delimitación marítima y cuestiones territoriales entre Qatar Y Bahrein -Qatar c. Bahréin-); Io de octubre de 2002 (Frontera terrestre $Y$ marítima entre Camerún y Nigeria -Camerún c. Nigeria; Guinea Ecuatorial interviniente-); I7 de diciembre de 2002 (Soberanía sobre Pulau Ligitan y Pulau Sipadan Indonesia/Malasia-); I8 de diciembre de 2003 (Demanda de revisión de la sentencia de 11 septiembre 1992 en el asunto de la Controversia fronteriza terrestre, insular y marítima (El Salvador/Honduras; Nicaragua interviniente) -El Salvador c. Honduras-); i2 de julio de 2005 (Controversia fronteriza -Benín/Níger-); 8 de octubre de 2007 (Controversia territorial $y$ marítima entre Nicaragua y Honduras en el Mar Caribe -Nicaragua c. Honduras-); 23 de mayo de 2008 (Soberanía sobre Pedra Branca/Pulau Batu Puteh, Middle Rocks Y South LedgeMalasia/Singapur-); I9 de noviembre de 2012 (Controversia territorial y marítima Nicaragua c. Colombia-); y 16 de abril de 2013 (Controversia fronteriza -Burkina Faso/Níger-);. Sin olvidar, el conocido asunto relativo al estatuto jurídico de Groenlandia Oriental resuelto en I933 por su antecesor, la Corte Permanente de Justicia Internacional (en adelante CPJI) ${ }^{4}$.

A estas sentencias habría que sumarles algunas otras decisiones adoptadas en otros asuntos contenciosos y consultivos, que de una $u$ otra forma aluden a cuestiones que guardan relación con la atribución de soberanía territorial; tales como la sentencia de i2 de abril de I960 en el asunto del Derecho de paso por territorio indio (Portugal c. India); del dictamen consultivo sobre el Sahara Occidental de i6 de octubre de I975; de la sentencia de I3 de diciembre de 2007 sobre excepciones preliminares en la controversia territorial $y$ marítima entre Nicaragua y Colombia; o la de I3 de julio de 2009 resolviendo la controversia relativa a los derechos de navegación y derechos conexos (Costa Rica c. Nicaragua). Además, actualmente, están pendientes de solución ante la Corte dos asuntos con importantes connotaciones territoriales: la demanda de interpretación de la sentencia de 15 de junio de 1962 en el asunto del Templo de Preah Vihear (Camboya c. Tailandia), y la demanda presentada por Bolivia contra Chile el 24 de abril de 2013 en relación con su pretendida salida al mar.

Este amplio bagaje jurisprudencial ha generado como resultado toda una serie de principios y reglas relativas al arreglo de las controversias territoriales que revisten una importancia fundamental, no sólo para la solución de este tipo de disputas, sino también de cara al planteamiento que los propios Estados partes en un contencioso territorial ante la CIJ deban hacer de sus propias pretensiones, con el objetivo de conseguir el mejor resultado, cual es que les sea atribuida la soberanía sobre el territorio en disputa.

Internacional. Análisis crítico de la Jurisprudencia internacional, Bilbao, Editorial de la Universidad del País Vasco, 20I0; a la que remitimos.

${ }^{4}$ PICJ, serie A/B. $n^{\circ} 53$ (http://www.icj-cij.org/pcij/serie_AB/AB_53/oI_Groenland_Oriental_Arret.pdf; fecha de consulta I3.5.20I3). 
Cierto es que cada controversia territorial se caracteriza por sus propios rasgos (la tipología del terreno, la longitud o extensión de la frontera en su caso, la existencia o no de tratados, las manifestaciones de soberanía, pasado colonial...); que cada contencioso presenta unas características propias que el juez deberá tener en cuenta. Esto significa que no se puede hablar en absoluto, in abstracto, de un arreglo automáticamente aplicable a toda controversia; cada caso es único y tendrá ser valorado de forma individual por sus propios méritos, atendiendo a las circunstancias que le son propias. En este sentido se ha manifestado la Corte en el asunto del Golfo de Maine:

« [...] each specific case is, in the final analysis, different from als the others, that it is monotypic and that, more often than not, the most appropriate criteria. and the method or combination of methods most likely to yield a result consonant with what the law indicates, can only be determined in relation to each particular case and its specific characteristics ${ }^{5}$.

No obstante lo anterior, la vasta práctica existente en la materia nos muestra que, salvo raras excepciones (y éstas siempre se han dado en el ámbito arbitral, no en el judicial), la solución de los contenciosos territoriales se sustancia aplicando los principios jurídicos y las reglas que la propia $\mathrm{CIJ}$ ha establecido a través de su jurisprudencia, y que trataremos de sintetizar en las páginas que siguen.

\section{La irrelevancia de la distinción entre conflictos de delimitación y conflictos de adquisición}

En relación con el territorio estatal dos son las cuestiones que tradicionalmente han preocupado, e incluso enfrentado, a los Estados: una, la correspondiente a su delimitación, esto es, al trazado de fronteras; otra, la relativa a la posibilidad de adquisición de soberanía territorial. En este sentido, cuando existen divergencias entre los Estados a este respecto se distingue entre conflictos de delimitación y conflictos de adquisición; una clasificación que se asienta en el entendimiento de que mientras los primeros se refieren al trazado del límite de sus territorios respectivos, los segundos oponen a los Estados respecto de la soberanía sobre una porción de territorio.

Tal diferenciación, que puede resultar práctica y operativa en un plano puramente teórico, se difumina en la práctica judicial y arbitral, no tiene valor absoluto, y resulta fútil, existiendo una clara interrelación entre la delimitación y la adquisición de la soberanía territorial, pues tanto los problemas fronterizos como los de adquisición son parte de una cuestión mayor, la relativa a la soberanía territorial. Así lo ha manifestado la CIJ asunto de la controversia fronteriza entre Burkina Faso y Malí:

«I7. Les Parties ont longuement discuté de la qualification du présent différend au regard d'une distinction parfois faite en doctrine entre «conflits frontaliers» ou «conflits de délimitation» et «conflits d'attribution territoriale». Selon cette distinction, les premiers viseraient les operations de délimitation portant sur ce qu'on a pu appeler une parcelle géographiquement non autonome [...] dans la très grande majorité des cas, comme en l'espèce, la distinction ainsi schématisée ne se résout pas ultimement en un contraste de genres mais exprime bien plutôt une différence de degré dans la mise en oeuvre de l'opération considérée. En effet chaque délimitation, aussi étroite que soit la zone

\footnotetext{
${ }^{5}$ ICJ Reports, I984, p.290, pa.8I.
} 
controversée que traverse le tracé, a pour conséquence de repartir les parcelles limitrophes de part et d'autre de ce tracé [...] Par ailleurs l'effet d'une décision judiciaire, qu'elle soit rendue dans un conflit d'attribution territoriale ou dans un conflit de délimitation, est nécessairement d'établir une frontière. Il n'est pas sans intérêt de relever que certaines conventions récentes de codification emploient des expressions telles que «traité établissant une frontière» ou «frontière établie par un traité» pour englober les traités de délimitation aussi bien que les traités d'attribution ou de cession (voir convention de Vienne sur le droit des traités, art. 62; convention de Vienne sur la succession d'Etats en matière de traités, art. II).» ${ }^{6}$

La consecuencia inmediata que encontramos de la intrascendencia de esta clasificación es que, situados en una denominada «controversia fronteriza», los Estados implicados alegan como fundamento de sus pretensiones -y la CIJ los toma en consideración-, no sólo estrictos criterios de delimitación de fronteras, sino también algún que otro modo de adquisición de la soberanía territorial, en concreto, la posesión efectiva del territorio. Así ocurrió, por ejemplo, en la mencionada Controversia fronteriza entre Burkina Faso y Malí, en la Controversia fronteriza entre El Salvador y Honduras, en el asunto de la Frontera terrestre entre Camerún y Nigeria, y en la Controversia fronteriza entre Benín y Níger; en todos ellos, calificados como conflictos de fronteras, los Estados presentaron y la Corte valoró -y tuvo en cuenta- argumentos propios de los conflictos de adquisición, en concreto, las efectividades desplegadas por las Partes. Y lo mismo puede suceder cuando la controversia territorial es tildada, a priori, de adquisición; podemos encontrarnos que los Estados invoquen -y la Corte aplique- un tratado de delimitación fronteriza como fundamento para que le sea atribuida la soberanía sobre el territorio en disputa. Así ocurrió, entre otros, en el asunto de la Soberanía sobre ciertas parcelas fronterizas, sentenciado a favor de Bélgica en base a un Tratado fronterizo de I843; o en la controversia entre Camerún y Nigeria, en la que la CIJ atribuyó a Camerún la soberanía sobre la Península y la Isla de Bakassi tomando como fundamento un Acuerdo anglo-alemán de I9I3.

No obstante lo anterior, resulta igualmente reseñable de la jurisprudencia de la CIJ su contribución a la fijación de un concepto unívoco de lo que debe entenderse por frontera. Muy clara resulta, entre otras, la definición de frontera facilitada en el asunto de la Controversia fronteriza entre Benín y Níger:

«Cette solution est conforme à la conception générale selon laquelle une frontière marque la séparation des souverainetés étatiques, autant sur la surface terrestre que dans le sous-sol et l'espace atmosphérique surjacent.»

\footnotetext{
${ }^{6}$ CIJ Recueil, i986, p.563, pa.I7. En sentido idéntico se ha manifestado la jurisprudencia arbitral; así el tribunal arbitral que resolvió el asunto de la Laguna del Desierto, afirmó que «lo mismo da que la divergencia existente entre las Partes sobre el trazado de la frontera se traduzca igualmente en una divergencia relativa a la atribución de los espacios territoriales, pues esto no modifica la naturaleza de la función del Tribunal» (ILR, vol.II3, pa.I58).

${ }^{7}$ CIJ Recueil, 2005, p.I42, pa.I24. Esta misma definición se reproduce en el asunto relativo a la Delimitación en el Mar Negro (Rumanía c. Ucrania) (ICJ Reports, 2009, p.23, pa.64).
} 


\section{Los modos de atribución del título de soberanía territorial derivados de una situación de hecho}

Es evidente que en el marco de los conflictos territoriales, resulta de importancia central determinar cuáles son los distintos mecanismos o modos a través de los cuales los Estados pueden adquirir soberanía territorial según el Derecho internacional. A este respecto, superada la clásica distinción entre modos originarios y modos derivados, los distintos mecanismos de atribución del título de soberanía territorial se articulan en torno a dos categorías: modos derivados de una situación de hecho y modos derivados de un título jurídico ${ }^{8}$. Entre los primeros suele mencionarse la ocupación, la prescripción y la accesión (al margen del ya obsoleto de la conquista o anexión territorial); mientras los segundos incluirían la cesión, la adjudicación, la sucesión a tratados de fronteras, y el principio del uti possidetis iuris.

Sobre este particular, resulta interesante realizar algunas observaciones a la luz de la jurisprudencia de la Corte. La primera es que, como señaló la CIJ en el asunto de la controversia fronteriza entre Burkina Faso y Mali (pa.I8), cuando hablamos de título de soberanía territorial debemos tener presente que el término título cuenta en Derecho internacional con una doble acepción, pudiendo hacer referencia tanto a cualquier medio de prueba susceptible de establecer la existencia de un derecho, como a la fuente misma de este derecho. En este sentido, genéricamente constituyen título aquellos hechos que el ordenamiento juzga capacitados para conferir un derecho, esto es, la causa o fundamento de un derecho; pero también se llama título al documento invocado para determinar la existencia de ese derecho, esto es, a los medios de prueba.

Por otra parte, por lo que se refiere a los distintos modos adquisitivos anteriormente citados, observamos que mientras los diferentes modos derivados de un título jurídico señalados han sido todo ellos invocados y aplicados en mayor o menor medida -siendo los tratados de fronteras y el uti possidetis iuris los que han sido objeto de una mayor aplicación práctica-, no ocurre lo mismo con los modos derivados de una situación de hecho. Resulta que el único modo fáctico aplicado por la CIJ ha sido la ocupación territorial, lo que le convierte en el modo de adquisición derivado de una situación de hecho por excelencia. Así, en ninguno de los asuntos anteriormente referidos se ha hecho alusión alguna a la accesión, ni por parte de los Estados, ni por la Corte; situación igualmente aplicable respecto de la conquista o anexión territorial.

Más interesante resultan los pronunciamientos judiciales con relación a la prescripción -modo conflictivo donde los haya-, no tanto por lo que dice, como por lo que no dice. En efecto, si bien hemos mencionado la prescripción como uno de los modos adquisitivos de la soberanía territorial -inclusión que obedece a la influencia del derecho romano en este ámbito-, cierto es que su consideración como tal es más que discutida, contando tanto con adeptos como con detractores. Más aún, no encontramos en la abundante práctica sobre la materia -no sólo judicial, sino también arbitral-, ni un solo asunto en el que se haya aplicado este modo para atribuir la soberanía sobre un territorio; por lo que no es exagerado afirmar que su status en el Derecho internacional resulta cuando menos incierto.

\footnotetext{
${ }^{8}$ El autor de dicha clasificación fue P. REUTER (Derecho Internacional público, -traducción del profesor Puente Egido-, Barcelona, I962, p.III).
} 
A este respecto, la CIJ, si bien ha tenido ocasión de manifestarse sobre la validez de la prescripción en Derecho internacional en dos contenciosos territoriales, lo cierto es que no ha querido pronunciarse de manera expresa. En este sentido, la primera vez que se invocó ante la Corte la aplicación de la prescripción fue en el asunto de la Isla de Kasili/Sedudu; concretamente, fue Namibia quien lo alegó, frente al título jurídico (tratado de I89o) que ostentaba Botswana y le atribuía la soberanía sobre la isla. Llegado el momento de analizar este argumento, la CIJ manifiesta:

«97. For present purposes, the Court need not concern itself with the status of acquisitive prescription in international law or with the conditions for acquiring title to territory by prescription. It considers, for the reasons set out below that the conditions cited by Namibia itself are not satisfied in this case and that Namibia's argument on acquisitive prescription therefore cannot be accepted»?

La segunda y última, ha sido en 2008 respecto de la soberanía de Pedra Branca/Pulau Batu Puteh, en el contencioso entre Malasia y Singapur. En este asunto, la Corte, tras rechazar hablar de prescripción -aduciendo que Singapur expresamente había alegado que no era aplicable (pa.I23-I24)-, decidió la atribución de la mencionada isla a favor de Singapur tomando como fundamento de su decisión dos circunstancias: la posesión efectiva de la misma a título de soberano por parte de Reino Unido/Singapur, y la ausencia de protesta -aquiescencia- frente a dicha posesión por Johor/Malasia que era el soberano originario de la isla (pa.273-275). Es evidente que tales factores aplicados por la Corte constituyen los elementos caracterizadores de la prescripción adquisitiva. Sin embargo, la CIJ elude en todo momento utilizar dicho término para justificar su decisión, optando por la innovadora fórmula «acuerdo tácito+aquiescencia»; que parece significar que se ha producido de facto una cesión territorial, no mediante un tratado -que es lo habitual-, sino a través del comportamiento recíproco de las partes.

A nuestro juicio, la posición claramente evasiva de la CIJ para pronunciarse acerca de la vigencia o no de la prescripción, así como el circunloquio inventado para no llamar como tal a lo que parece serlo, no hacen sino confirmar que estamos ante un modo adquisitivo de dudosa existencia en Derecho internacional, y que no existe jurisprudencia internacional alguna -ni arbitral, ni judicial- que lo apoye.

En esta línea, la CIJ también rechaza «la consolidación histórica del título» como modo adquisitivo reconocido en Derecho internacional. Su posición es muy clara a este respecto: «the notion of historical consolidation has never been used as a basis of title in other territorial disputes, whether in its own or in other case law» ${ }^{10}$.

Por otra parte, por lo que se refiere a la ocupación territorial, se observa igualmente cómo de forma paulatina se ha ido dejando de lado completamente el uso del término «ocupación», para hablar de forma genérica de «posesión efectiva» del territorio o, en su caso, de «efectividades» -esto es, ejercicio continuo y pacífico de funciones de Estado sobre un territorio determinado-. En esta misma línea, en la valoración de la posesión efectiva u ocupación territorial se prescinde por completo de la apreciación del carácter de terra nullius o no del territorio en disputa. Resulta indiferente cómo era el territorio en sus orígenes

\footnotetext{
${ }^{9}$ ICJ Reports, I999, p.II05, pa.97.

${ }^{\text {10 }}$ Asunto de la Frontera terrestre entre Camerún y Nigeria, ICJ Reports, 2002, p.352, pa.65.
} 
remotos; lo realmente importante es la valoración de la prueba de los distintos actos realizados a título de soberano sobre el territorio disputado. Ya ocurrió en I933 en el asunto relativo al estatuto jurídico de Groenlandia Oriental, en el que en ningún momento se debate acerca del carácter nullius del territorio en disputa; en 1953 respecto de Minquiers y Ecrehous (p.53); en 2002 con relación a Pulau Ligitan y Pulau Sipadan (pa.Io8); y, más recientemente, en 2008 respecto de Pedra Branca, Middle Rocks y South Ledge (pa.I23). En todos ellos, la Corte consideró irrelevante el carácter de terra nullius o no del territorio en disputa, entendiendo que lo realmente importante era la valoración de la posesión efectiva. Lo que de facto supone una evolución del tradicional modo adquisitivo de la ocupación hacia la posesión efectiva o efectividades.

\section{La consolidación de los principales títulos jurídicos: uti possidetis iuris y principio de continuidad de los tratados de fronteras}

Por lo que se refiere a los títulos jurídicos, la jurisprudencia de la CIJ no hace sino confirmar el importante papel que juegan en la solución de los contenciosos territoriales dos principios generales de Derecho internacional, cuáles son, el principio del uti possidetis iuris, y el de continuidad de los tratados de carácter territorial -en particular los de fronteras-; reforzando aún más el carácter fundamental de ambos.

Esto resulta especialmente reseñable por lo que hace al uti possidetis iuris, principio que proclama el mantenimiento de las fronteras coloniales existentes en el momento de accesión a la independencia ${ }^{\text {II }}$. Este principio surge a principios del siglo XIX en el marco de la independencia de las colonias españolas en América $^{\mathrm{I}}$, al ser adoptado por numerosos Estados para dirimir sus cuestiones de límites, consistiendo en la práctica de establecer, en la medida de lo posible, sus fronteras mutuas siguiendo los límites que tenían cuando eran dependencias españolas en el momento inmediatamente anterior al de su accesión a la Independencia ${ }^{\text {I3 }}$. De esta forma, las fronteras administrativas se transforman en fronteras internacionales.

Nacido así como principio regional americano, su translación a otras esferas geográficas fue objeto de un amplio debate doctrinal al que puso término, finalmente, la CIJ al consagrarlo como principio general del Derecho internacional en el asunto de la Controversia fronteriza entre Burkina Faso y Mali (1986). Ésta era la primera vez que la

\footnotetext{
${ }^{\text {II }}$ Efectivamente, el uti possidetis iuris se define como «principe selon lequel doivent ètre respetées et maintenues en l'ètat les frontières coloniales héritées, au moment de leur indepéndence, par les nouveaux États» (vid. Pinho CAmpinos, J. DE, «L'actualité de l'uti possidetis», en SFDI, Colloque de Poitiers. La Frontière, París, i980, p.95).

${ }^{\mathrm{r} 2}$ El origen terminológico de la expresión uti possidetis se sitúa en el Derecho romano, concretamente se toma del Interdicto del Pretor, de tipo procedimental, que reza así:

«Uti nunc eas aedes, quibus de agitur, nec vi, nec clam, nec precario, ab altero possidetis, quo minus ita possideatis, vim fieri veto» («Prohíbo que se use de la fuerza para impedir a aquel de vosotros dos que al presente esté en posesión de las casas de que se trata, sin violencia, clandestinidad ni precario, que la posea como al presente la posee»). Vid. Digesto, libro 43, ti. I7, p.I.

Interdicto que, en forma abreviada se conoce como «uti possidetis, ita possideatis» (como poseéis, seguiréis poseyendo).

${ }^{\mathrm{r} 3}$ Precisamente, la alusión a la fecha de la independencia como punto de referencia en la determinación de los límites administrativos, es lo que lleva a hablar habitualmente de uti possidetis de I8Io y I82I, en cuanto ambos años constituyen una referencia válida en la proclamación de independencia de las colonias españolas de América del Sur, y América Central, respectivamente.
} 
Corte se enfrentaba a la aplicación del uti possidetis iuris en África, lo que le obligó a fundamentar y justificar en detalle el valor jurídico de dicha regla como «principio bien establecido de Derecho internacional», «regla de ámbito general», «principio de orden general» y «uno de los principios jurídicos más importantes» ${ }^{\mathrm{I}}$, estableciendo, no un mero obiter dictum, sino una contundente construcción jurídica al respecto. Concretamente, la Corte fundamenta la aplicación de este principio en África, por un lado, en el artículo 3 de la Carta de OUA, y por otro, en la Resolución de El Cairo (AGH/Res.I6) adoptada en julio de I964. Posteriormente, ha tenido ocasión de reforzar su propio pronunciamiento en el asunto de Controversia fronteriza entre Benín y $\mathrm{Níger}^{\text {I5 }}$, en el que reitera los argumentos expuestos en 1986, añadiendo la referencia al Acta Constitutiva de la Unión Africana, firmada en Lomé el iI de julio de 2000 por 53 Estados africanos, y que recoge como principio reconocido por la Unión Africana el del «respeto a las fronteras existentes en el momento de accesión a la independencia» (artículo 4 b), esto es, el principio del uti possidetis iuris.

Igualmente importante resulta la clarificación que hace la CIJ por lo que se refiere al ámbito material de aplicación del uti possidetis. Surgido en un puro contexto de establecimiento de fronteras, y concretamente fronteras terrestres, la jurisprudencia de la Corte ha consolidado su aplicabilidad más allá, pudiendo igualmente resultar aplicable como título jurídico para establecer la atribución de soberanía sobre un territorio determinado, así como para delimitar las fronteras marítimas. Así ha sido afirmado por la CIJ en el asunto de la controversia fronteriza terrestre, insular $y$ marítima entre El Salvador y Honduras, en el que la Sala sostiene que «ne doute pas que le point de départ de la détermination de la souveraineté sur les îles doive être l'uti possidetis juris de I82I», y que «le principe de l'uti possidetis juris devrait s'appliquer aux eaux du golfe ainsi qu'aux terres ${ }^{16}$. Una afirmación reiterada en los más recientes asuntos de la controversia territorial $y$ marítima entre Nicaragua y Honduras en el Mar Caribe (2007) y de la controversia territorial $y$ marítima entre Nicaragua y Colombia (2012) ${ }^{17}$.

Igual de clara es la posición de la CIJ por lo que se refiere al principio de continuidad de los tratados de fronteras $y$ de carácter territorial. Desde que el 3 de septiembre de I783, Gran Bretaña y EEUU concluyeran el Tratado de Paz de París, por el que éstos declaraban seguir manteniendo las fronteras y demás derechos y obligaciones territoriales establecidos por Gran Bretaña, el principio de continuidad se ha ido afianzando como principio general de Derecho internacional. A este respecto, tanto la práctica como la jurisprudencia internacional han venido a crear un clima de asentimiento generalizado entre los Estados en la idea de que el respeto a las fronteras heredadas del Estado predecesor posee un carácter obligatorio para los Estados de reciente independencia. La afirmación de principio es que la sucesión de Estados no afecta a los tratados de fronteras, de tal manera que éstos

\footnotetext{
${ }^{14}$ CIJ Recueil, I986, p.565, pa.20-2I, p.566, pa.24 y pa.26.

${ }^{15}$ CIJ Recueil, 2005, p.I08, pa.23.

${ }^{16}$ CIJ Recueil, I992, p.558, pa.333 y p.589, pa.386, respectivamente.

${ }^{17}$ Recordando su pronunciamiento de I992, la CIJ sostiene que «commencera par faire observer que l'uti possidetis juris peut, en principe, s'appliquer aux possessions territoriales situées au large des côtes et aux espaces maritimes» (CIJ Recueil, 2007, p.707, pa.156). En sentido similar se manifiesta en su sentencia de iو de noviembre de 2012 (pa.57); véase el texto en http://www.icj-cij.org/docket/files/124/17i65.pdf (fecha de consulta I3.5.2013).
} 
se constituyen en una excepción a la regla de que el Estado de reciente independencia no hereda ipso iure los tratados de su predecesor, tal y como consagra el artículo in de la Convención de Viena sobre sucesión de Estados en materia de tratados de 23 de agosto de $1978^{18}$.

La CIJ ha tenido ocasión de aplicar este principio de continuidad en varios contenciosos territoriales, sin dejar lugar a dudas acerca de la plena vigencia y operatividad del mismo. Tal es el caso del asunto del Templo de Preah Vihear, basado en la aplicación de un tratado de 1904 concluido entre Tailandia y Francia, al que sucede Camboya. Igualmente, en la sentencia de 24 de febrero de I982, emitida con ocasión de la delimitación de la plataforma continental entre Túnez y Libia, la Corte establece como una de las pautas a seguir, la de la prolongación de la frontera terrestre; frontera que a su juicio estaba perfectamente definida en un Tratado de I9 mayo i9ıo, entre Túnez y el Imperio Otomano, al que estaban vinculadas ambas Partes en calidad de Estados sucesores y en aplicación de la «rule of continuity ipso iure of boundary and territorial treaties» ${ }^{\text {t9 }}$. El principio de continuidad a tratados de fronteras y de carácter territorial está también en el fundamento de la sentencia de 3 de febrero de 1994 en la Controversia territorial (Jamahiriya árabe libia y Chad), basada en el tratado franco-libio de io de agosto de I955; en la de I3 de diciembre der999 en el asunto de la Isla de Kasikili/Sedudu (Botswana y Nambia), fundamentada en el tratado anglo-alemán de I de julio de I890; y en la de ıo de octubre de 2002 en el asunto de la Frontera terrestre y marítima entre Camerún y Nigeria, en la que la Corte aplica varios tratados anglo-franceses (Declaración Milner-Simon de I9I9, Declaración ThomsonMarchand de I929-30, y canje de notas Henderson-Fleuriau de I93I), así como los acuerdos anglo-alemanes de II de marzo y I2 de abril de I9I3. No existe, pues, resquicio alguno en la jurisprudencia de la CIJ con relación a la aplicabilidad de este principio.

Al hilo de la aplicación de los referidos tratados en los mencionados asuntos, la subsiguiente tarea que abordó la CIJ fue la de la interpretación de los mismos. A este respecto debemos señalar que la Corte se mantiene fiel a la aplicación de las reglas interpretativas recogidas en los artículos 3I, 32 y 33 del Convenio de Viena sobre Derecho de los Tratados de ig69. Resultando así que su prioridad ha sido siempre el texto y contexto del propio tratado, el sentido ordinario de los términos empleados, en consonancia con su objeto y fin; el recurso a los medios complementarios del artículo 32 ha sido pertinente para la CIJ, no tanto para confirmar la interpretación generada con las reglas del artículo 3I, sino sobre todo cuando éstas se han mostrado claramente insuficientes.

Por último, por lo que se refiere a títulos jurídicos, indicar el valor residual que ha ocupado siempre la cartografía como elemento en el proceso de atribución de la soberanía territorial. Nuevamente, la jurisprudencia de la Corte es muy clara en este punto; resultando así que, en asuntos como los de Burkina Faso/Mali, El Salvador/Honduras, Isla de

\footnotetext{
${ }^{18}$ Sin duda, la razón de ser de esta regla descansa en el particular carácter que presenta este tipo de tratados. En este sentido, Tran Van Minh afirma que «on considère que les traités territoriaux sont d'une nature particulière; ils créent ou transferent, ou reconnaissent l'existence de certains droits permanents, qui acquièrent ou maintiennent une existence séparée et une validité indépendante des traités qui les ont crées.» («Remarques sur le principe de l'intangibilité des frontières» en Peuples et Etats du tiers monde face à l'ordre international, París, I978, p.5I).

En sentido similar, la CIJ ha afirmado en su sentencia de I3 de diciembre de 2007, en el asunto de la controversia territorial y marítima (Nicaragua c. Colombia), excepciones preliminares, que «rappelle que c'est un principe de droit international qu'un régime territorial établi par traité «acquiert une permanence que le traité lui-même ne connaît pas nécessairement» et que la persistance de ce régime ne dépend pas de la survie du traité par lequel ledit régime a été convenu» (CIJ Recueil, 2007, p.869, pa.89).
}

${ }^{19}$ CIJ Recueil, I982, pp.65-66, pa.83-84 y 85. 
Kasikili/Sedudu, Qatar y Bahrein, o Pedra Branca, Middle Rocks y South Ledge, la Corte ha rechazado sin paliativos la pertinencia de los mapas como título autónomo válido per se para atribuir la soberanía territorial, manifestándose en términos como éstos:

«Whether in frontier delimitations or in international conflicts, maps merely constitute information which varies in accuracy from case to case; of themselves, and by virtue solely of their existence, they cannot constitute a territorial title, that is, a document endowed by international law with intrinsic legal force for the purpose of establishing territorial rights...

...The only value they possess is as evidence of an auxiliary or confirmatory kind, and this also means that they cannot give the character of a rebuttable or «iuris tantum» presumption such as to effect a reversal of the onus of proof $\gg^{20}$.

En esta línea, en el reciente asunto de la controversia territorial y marítima (Nicaragua c. Colombia), la CIJ ha recordado su propia jurisprudencia afirmando que «les cartes n'ont généralement qu'une portée limitée en tant que preuve d'un titre de souveraineté»; lo que le lleva a admitir la prueba cartográfica presentada por Colombia solo en la medida en que sirve para confirmar la posesión colombiana de las formaciones marítimas en disputa ${ }^{2 \mathrm{~T}}$.

Resulta, pues, evidente que el uso de los mapas como prueba de resolución de disputas fronterizas ha sido siempre justamente restringido ocupando una parte colateral mas que principal en la regla del mejor título. De tal forma, que su valor como título jurídico autónomo se hace depender del hecho de que forme parte de un tratado internacional, como anexo al mismo; tal y como sucedió en el asunto relativo al Templo de Préah Vihéar ${ }^{22}$ o en el más reciente de la controversia fronteriza (Burkina faso/Níger). ${ }^{23}$

\section{La interacción entre los títulos jurídicos y la posesión efectiva}

Es necesario indicar que la adquisición de un título de soberanía sobre un territorio no suele responder al juego en exclusiva de un solo modo, sino que normalmente concurren varios modos en ese proceso. En este sentido, resulta realmente frecuente en la práctica jurisprudencial que un título jurídico -habitualmente un tratado de fronteras o el uti possidetis iuris- y la posesión efectiva o efectividades, entren en una relación dialéctica, presentándose entremezclados en controversias territoriales caracterizadas porque, mientras una parte reivindica la soberanía apoyándose en un título jurídico, la otra alega la posesión efectiva del territorio en cuestión.

Planteada esta disyuntiva en la controversia fronteriza entre Burkina Faso y Malí, la CIJ estableció una explícita construcción jurídica, sentando las cuatro posibles hipótesis de interacción entre ambos modos adquisitivos (pa.63):

\footnotetext{
${ }^{20}$ Asunto de la controversia fronteriza (Burkina Faso/Mali), CIJ Recueil, I986, pp.582-583, pa.53 y 56.

${ }^{21}$ Sentencia de I9 de noviembre de 20I2, pa.I00 y I02 (http://www.icj-cij.org/docket/files/I24/I7I65.pdf; fecha de consulta I3.5.2013).

${ }^{22}$ CIJ Recueil, I962, p.2I.

${ }^{23}$ La insuficiencia del uti possidetis iuris para determinar la frontera entre Burkina Faso y Níger, lleva a la Corte a establecer como trazado el fijado en un mapa del IGN de i960, en la medida en que el art.2 del tratado de 1987 celebrado entre ambos Estados remitía al mismo en caso de insuficiencia de pruebas para el trazado de la frontera (pa.68, de la sentencia de I6 de abril de 20I3, http://www.icj-cij.org/docket/files/I49/I7307.pdf, fecha de consulta $13 \cdot 5 \cdot 2013)$.
} 
I. Si el hecho corresponde con el derecho, esto es, si la posesión coincide con el título jurídico: las efectividades sólo pueden confirmar el ejercicio del derecho nacido del título jurídico.

2. En el caso de que el hecho no corresponda con el derecho, que el territorio sea ocupado por un Estado distinto al que posee el título jurídico: preminencia del título jurídico sobre las efectividades.

3. Si el título jurídico es ambiguo o impreciso y no demuestra de manera precisa a quien corresponde la soberanía, la posesión efectiva debe retenerse para interpretar o completar el título.

4. Si no hay título jurídico, se debe tomar inevitablemente en cuenta la posesión efectiva.

Toda la jurisprudencia de la CIJ relativa a controversias territoriales responde sin fisuras a este juego de interacciones, que toma como principio de base la primacía del título jurídico sobre la posesión efectiva del territorio ${ }^{24}$. Contamos con más de cincuenta años ya de una jurisprudencia progresiva de la Corte Internacional de Justicia consolidando paulatinamente la primacía -e incluso me atrevería a apuntar, la «inmutabilidad»- del título jurídico. Desde que en I959 resolviera la controversia relativa a la soberanía sobre ciertas parcelas fronterizas entre Bélgica y Países Bajos, sobre la base del tratado de I843 sin dar ninguna posibilidad a las efectividades posteriores desplegadas por Países Bajos en la zona controvertida -a la que siguió en la misma línea la del Templo de Préah Vihéar (Camboya c. Tailandia) en I962-, la Corte ha ido entretejiendo poco a poco una telaraña jurisprudencial clara y sin paliativos, en la que la posesión efectiva queda atrapada sin remisión cuando se enfrenta a un título jurídico, cuyo cénit lo constituye el ya citado asunto de Burkina Faso y Mali.

A éste le han seguido otros en los que la CIJ ha tenido oportunidad de citarse a sí misma para seguir consolidando este principio de primacía del título jurídico. Tal es el caso de la Controversia fronteriza terrestre, insular y marítima (El Salvador/Honduras; Nicaragua interviniente), aplicando el uti possidetis; de la Controversia territorial (Jamahiriya árabe libia/Chad) resuelta sobre la base del Tratado franco-libio de 1955; del asunto relativo a la Isla de Kasikili/Sedudu (Botswana y Namibia), basado en el Tratado anglo-alemán de I89o; de la Delimitación marítima y cuestiones territoriales entre Qatar y Bahrein, una parte de cuya sentencia estuvo fundamentada en una decisión adoptada por Gran Bretaña el I de julio de I939; de la Frontera terrestre y marítima entre Camerún y Nigeria (Camerún c. Nigeria; Guinea Ecuatorial interviniente) donde la Corte aplica varios tratados internacionales para resolver la múltiple controversia (Declaración Milner-Simon de I9I9, Declaración Thomson-Marchand de I929-30, y canje de notas Henderson-Fleuriau de I93I, así como los acuerdos anglo-alemanes de I9I3); y de la Controversia fronteriza (Benín/Níger) decidida en aplicación del uti possidetis iuris.

Resulta así que la regla está clara: si existe un título jurídico válido y perfecto cuya aplicación e interpretación consigue decidir sin problema la atribución del título de

${ }^{24}$ Un análisis más detallado de este juego de interacciones en la jurisprudencia internacional puede consultarse en KoHen, M. G., «La relation titres/effectivités dans le contentieux territorial à la lumière de la jurisprudence récente», Revue Générale de Droit International Public, 2004, t. 108/3, pp. 56I-596. 
soberanía territorial, la posesión efectiva se excluye, salvo aquella que sirva para confirmarlo o interpretarlo. Ahora bien, si el título jurídico es incompleto o bien no existe título jurídico alguno que sea aplicable al caso para resolver la controversia, también la regla es clara: hay que recurrir a la posesión efectiva del territorio, que actúa como complementaria o sustitutoria, según el caso, del título jurídico. En tales supuestos, habrá que decidir la atribución de la soberanía territorial a la Parte que presente una mejor prueba de actos realizados en dicho territorio a título de soberano. Así lo corroboran los asuntos de la Controversia fronteriza terrestre, insular y marítima (El Salvador/Honduras; Nicaragua interviniente), de la Controversia fronteriza (Benín/Níger), de la Controversia territorial $y$ marítima entre Nicaragua y Honduras en el Mar Caribe, y de la controversia territorial $y$ marítima (Nicaragua c. Colombia), en los que la insuficiencia del título jurídico concretamente, el uti possidetis iuris- para resolver algunas partes del contencioso obligaron a la CIJ a acudir a las efectividades como medio complementario del título jurídico.

Por lo que se refiere a inexistencia de título jurídico, los asuntos relativos a la Soberanía sobre Pulau Ligitan y Pulau Sipadan, y a la Soberanía sobre Pedra Branca/Pulau Batu Puteh, Middle Rocks y South Ledge, confirman que en ausencia de título jurídico -en ambos la Corte rechazó la operatividad de los distintos tratados coloniales invocados por las Partes-, es imperativo el recurso a la valoración de la posesión efectiva del territorio en disputa.

\section{Las efectividades y el principio de relatividad de la posesión efectiva}

Situados en el plano concreto de valoración de la posesión efectiva, para adquirir válidamente un título de soberanía sobre un territorio, el Derecho internacional exige la confluencia de dos elementos, a saber, la intención de actuar como soberano, y el despliegue de autoridad sobre dicho territorio mediante el ejercicio continuo y pacífico de funciones de Estado -lo que conocemos como efectividades-. Resulta, pues, imperativo para fundamentar un título territorial que se establezca una cierta relación entre el sujeto y el objeto, que el primero actúe eficazmente sobre el segundo. De esta forma, la existencia de soberanía territorial aparece ligada a las manifestaciones de su ejercicio, erigiéndose éste como elemento constitutivo por el cual la soberanía se adquiere y se mantiene. Por eso, lo que realmente interesa, a efectos de atribución de soberanía, son los actos a través de los cuales se ejerce ésta, comprendiendo cualquier actividad desplegada por un órgano estatal a título de soberano. A la luz de la jurisprudencia que venimos examinando, resulta que no existe una 'actividad tipo' que realizada suponga la atribución de la soberanía. Esto es algo que debe valorarse en cada caso concreto, siendo fundamental que se trate de actos realizados en nombre del Estado y a título de soberano: legislación, despliegue de fuerzas armadas y policiales, ejercicio de jurisdicción civil y penal, recaudación de impuestos, actos de registro, son algunos de los actos que la Corte ha valorado como probatorios de posesión efectiva $^{25}$.

Ahora bien, la exigencia de posesión efectiva del territorio a través de la materialización de diversos actos de soberanía estatal debe relativizarse en atención a la

\footnotetext{
${ }^{25}$ Para un examen en detalle de la prueba de la posesión efectiva, véase, KoHEN, M.G., Possession contestée et souveraineté territoriale, Paris, Presses Universitaires France, I997; y LóPEZ MARTíN, A.G., El territorio estatal en discusión: la prueba del título, Madrid, McGraw Hill, I999.
} 
naturaleza y características del territorio, a su carácter habitable o no, así como al tamaño de su población si estuviera habitado. Esta relativización de la efectividad enlaza con una amplia y consolidada jurisprudencia internacional -arbitral y judicial-. A este respecto, señala la CPJI en el asunto del estatuto jurídico Groenlandia oriental, resaltando las peculiares características que presentaba Groenlandia, que

«it is impossible to read the records of the decisions in cases as to territorial sovereignty without observing that in many cases the tribunal has been satisfied with very little in the way of the actual exercise of sovereign rights, provided that the other State could not make out a superior claim. This is particularly true in the case of claims to sovereignty over areas in thinly populated or unsettled countries» ${ }^{26}$.

Las zonas polares, los desiertos, las áreas montañosas, las islas pequeñas, rocosas, deshabitadas o de difícil acceso en las que el establecimiento de manera continua resulta realmente complejo, quedan claramente englobadas en esa referencia que hace la Corte a «áreas deshabitadas o escasamente pobladas» -a las que podríamos calificar como «situaciones territoriales particulares»-, y, en consecuencia, sometidas al principio de relatividad de la efectividad. Este principio trae como consecuencia directa que, en tales territorios, la posesión efectiva puede quedar perfectamente establecida a través de un limitado y en ocasiones exiguo número de actos de autoridad estatal. La aplicabilidad de este principio queda corroborada por la jurisprudencia de la CIJ, quien la ha aplicado en los siguientes recientes asuntos: Delimitación marítima y cuestiones territoriales entre Qatar $y$ Bahrein, Soberanía sobre Pulau Ligitan y Pulau Sipadan (Indonesia/Malasia), Controversia territorial y marítima entre Nicaragua y Honduras en el Mar Caribe, y Soberanía sobre Pedra Branca/Pulau Batu Puteh, Middle Rocks y South Ledge (Malasia/Singapur); en estos casos, una actividad tan simple como es la colocación de sistemas de ayuda a la navegación balizas, faros...- en los concernientes islotes y cayos, así como su posterior mantenimiento y gestión, fueron prueba suficiente para la Corte de posesión efectiva de los mismos.

A la luz de los mencionados asuntos, queremos hacer notar la creciente importancia que han cobrado las diferentes formaciones marítimas -cayos, islas, rocas...- en los conflictos de delimitación marítima; habida cuenta que la determinación de su soberanía supone un factor fundamental en el trazado de la frontera marítima. Pues es evidente que un tribunal internacional no puede fijar los límites marítimos entre los Estados sin pronunciarse antes acerca de la situación de las formaciones marítimas y su soberanía, pues son susceptibles de influir en la delimitación. Ejemplarizantes en este sentido son los asuntos relativos a la Controversia territorial y marítima entre Nicaragua y Honduras en el Mar Caribe, y a la Controversia territorial $y$ marítima entre Nicaragua y Colombia.

A este respecto, debemos advertir que, como ha señalado la $\mathrm{CI}^{27}$, las elevaciones de bajamar, los bajíos descubiertos no son susceptibles de apropiación, y, por tanto, estarán sometidos a la soberanía del Estado en cuyo mar territorial se encuentran. Así de clara ha sido la Corte en su sentencia de I9 de noviembre de 20I2:

\footnotetext{
${ }^{26}$ P.C.I.J., serie $A / B, n^{o} 53$, I933, p.46.

${ }^{27}$ Tal ha sido afirmado en el asunto de la Delimitación marítima y cuestiones territoriales entre Qatar y Bahrein (ICJ Reports, 200I, pp.IoIo-I03, pa.205-206), y en el relativo a la Soberanía sobre Pedra Branca/Pulau Batu Puteh, Middle Rocks y South Ledge (Malasia/Singapur) (ICJ Reports, 2008, pa.297-298).
} 
«Il est bien établi en droit international que les îles, si petites soient-elles, sont susceptibles d'appropriation (voir, par exemple, Délimitation maritime et questions territoriales entre Qatar et Bahreïn (Qatar c. Bahreïn), fond, arrêt, C.I.J. Recueil 2001, p. IO2, par. 206). En revanche, les hauts-fonds découvrants ne peuvent faire l'objet d'appropriation, et ce, bien que l'«Etat côtier exerce sa souveraineté sur les hauts-fonds découvrants situés dans sa mer territoriale, puisqu'il exerce sa souveraineté sur la mer territoriale elle-même» (ibid., p. IOI, par. 204) et que les hauts-fonds découvrants situés à l'intérieur de la mer territoriale puissent être pris en considération aux fins de mesurer la largeur de celle-ci» ${ }^{28}$.

\section{La conducta recíproca de las partes}

Ante una situación concreta de hecho o de derecho, respecto de la cual existen pretensiones concurrentes y contradictorias por parte de dos Estados distintos, el comportamiento de uno de ellos nunca es irrelevante para el otro, especialmente cuando la conducta de un Estado impone al otro la obligación de protestar si estima que afecta un derecho propio, y no lo hace. La aquiescencia y el estoppel juegan entonces un papel primordial en la decisión final de la controversia. Es precisamente en el ámbito de los contenciosos territoriales donde estas figuras se dan con mayor frecuencia y despliegan toda su operatividad ${ }^{29}$.

En esta línea, fue en el asunto relativo al Laudo arbitral del Rey de España de 23 diciembre 1906 (Honduras c. Nicaragua) donde la CIJ aplica por primera vez las figuras de la aquiescencia y el estoppel: lo hace respecto de la conducta pasiva de Nicaragua respecto del laudo de 1906 lo que le sirve para afirmar su validez (p.209). Posteriormente, recurre a estas instituciones -si bien de forma secundaria- en el asunto del Templo de Preah Vihear: el silencio de Tailandia de más de 50 años frente al mapa anexo al tratado de I904, que deriva en el posterior estoppel, son el claro fundamento de la validez del por el que se atribuye la soberanía a Camboya (p.32). Este mismo argumento -ausencia de protesta nicaragüense durante 50 años-, le sirve a la Corte para afirmar la validez del tratado de I928 en su sentencia de I3 de diciembre de 2007 sobre excepciones preliminares en la controversia territorial y marítima entre Nicaragua y Colombia (pa.79). Papel fundamental jugó la aquiescencia -afectando, en este caso, derechos derivados del principio del uti possidetis iuris- en el asunto de la controversia fronteriza terrestre, insular $y$ marítima entre El Salvador y Honduras; donde el reconocimiento explícito y, sobre todo, la aquiescencia de una de las Partes al comportamiento del otro -concretamente, la posesión del territorioaparecen como determinantes, tanto para el trazado de una parte de la frontera (pa.8o), como para el establecimiento de la soberanía sobre las islas en disputa (pa.364-367).

\footnotetext{
${ }_{28}$ Asunto relativo a la controversia territorial y marítima (Nicaragua c. Colombia), pa.26 (http://www.icjcij.org/docket/files/ı24/I7I65.pdf. Fecha de consulta I3.5.20I3). En esta línea, la Corte consideró que mientras los cayos de Alburquerque, del Este-Sudeste, Roncador, Serrana, Serranilla y Bajo Nuevo sí eran islas, no ocurría lo mismo con Quitasueño (pa.38); todo lo cual tuvo gran trascendencia en la delimitación marítima posterior.

${ }^{29}$ Para un análisis en detalle del papel que juega en Derecho internacional la conducta recíproca de los Estados, tanto en general, como en particular en materia de contenciosos territoriales, véase el trabajo de JimÉnEZ García, F., Los comportamientos recíprocos en Derecho Internacional. A propósito de la aquiescencia, el estoppel y la confianza legítima, Madrid, Dilex, 2002.
} 
Más recientemente, el argumento de la aquiescencia ha tenido un peso decisivo en el asunto de la Soberanía sobre Pedra Branca/Pulau Batu Puteh, Middle Rocks y South Ledge (Malasia/Singapur); pues, como ya hemos indicado, la CIJ atribuye la soberanía de Pedra Branca a Singapur basándose, tanto en los actos de posesión efectiva desplegados en dicha isla por Reino Unido/Singapur, como en la falta de protesta (aquiescencia) respecto de los mismo por parte de su soberano originario, Johor/Malasia (pa.273-275).

\section{Una importante institución procesal: la fecha crítica}

Se entiende por fecha crítica, la fecha después de la cual las acciones, el comportamiento de las Partes no puede afectar al resultado de la controversia, es decir, la fecha a partir de la cual los datos del litigio deben ser considerados como definitivamente fijados, de tal forma que los hechos posteriores no son pertinentes en la solución de la disputa $^{30}$.

Así concebida la fecha crítica, ésta cobra una importancia decisiva en las controversias territoriales, las cuales se caracterizan por alegar las Partes títulos contrapuestos, siendo en los contenciosos que presentan como modo de adquisición el de la posesión efectiva donde ésta se suscita con mayor frecuencia. Una mirada atenta a la práctica jurisprudencial nos confirma esta afirmación. En efecto, partiendo del viejo laudo arbitral de mediados del siglo XIX en el asunto de la Isla de Aves, hasta llegar a la reciente sentencia de la CIJ en el asunto de la controversia fronteriza terrestre, insular y marítima entre El Salvador y Honduras, observamos cómo la jurisprudencia internacional -tanto por vía arbitral como judicial- ha utilizado en reiteradas ocasiones la noción de fecha crítica como categoría jurídica de indudable importancia, para indicar el periodo dentro del cual las Partes pueden demostrar la consolidación de su titulo. En los casos en que juega la fecha crítica, la exacta determinación de ésta ocupa una importancia de primer orden. Y ello porque en torno a la misma se suscitan dos cuestiones de interés:

- a efectos de valorar la prueba concerniente a la soberanía anterior a la misma, denominándose «período crítico» al inmediatamente anterior a la fecha crítica;

- para establecer qué relevancia pueden tener los elementos de prueba posteriores a dicha fecha.

En este sentido se ha manifestado la CIJ:

«Dans le contexte d'un différend portant sur une délimitation maritime ou d'un différend relatif à la souveraineté sur un territoire, l'importance de la date critique consiste en ceci qu'elle permet de faire la part entre les actes accomplis à titre de souverain, qui sont en príncipe pertinents aux fins d'apprécier et de confirmer des effectivités, et ceux postérieurs à cette date, lesquels ne sont généralement pas pertinents en tant qu'ils sont le fait d'un Etat qui, ayant déjà à faire valoir certaines revendications dans le cadre d'un différend juridique, pourrait avoir accompli les actes en question dans le seul but d'étayer

${ }^{30}$ Cf. Dictionnaire de la terminologie du Droit International, París, Sirey, I960, p.I86. Para un estudio en detalle del valor de la fecha crítica en los contenciosos territoriales puede consultarse el trabajo clásico de SÁNCHEZ RODRÍGUEZ, L.I., «Fecha crítica, contenciosos territoriales y jurisprudencia internacional», en Hacia un nuevo orden internacional europeo. Estudios en homenaje al profesor D. Manuel Díez de Velasco, Madrid, Tecnos, I993, pp. 66I-680. 
celles-ci. La date critique marque donc le point à partir duquel les activités des Parties cessent d'être pertinentes en tant qu'effectivités.» ${ }^{3 \mathrm{~T}}$

Como posibles fechas a retener como «fecha crítica», G. Fitzmaurice propone las siguientes hipótesis ${ }^{32}$ :

- fecha de comienzo de la disputa;

- fecha en que una de las partes plantea por primera vez una reclamación formal sobre el territorio;

- fecha en que cristaliza la controversia de forma definitiva;

- fecha en que una de las partes inicia un procedimiento de arreglo;

- fecha en que se pone en funcionamiento algún procedimiento de arreglo;

- fecha en que se propone someter la controversia a un método jurisdiccional.

A este respecto debemos señalar que, si bien las Partes del contencioso pueden indicar las posibles fechas críticas del mismo -propondrán, sin duda, la fecha que mejor convenga a sus intereses-, es competencia del juez determinar la fecha crítica; puede también determinar que existe más de una fecha crítica -asuntos de Minquiers $y$ Ecrehous, y de Pedra Branca, Middle Rocks y South Ledge-; o, incluso, puede suceder que el juez considere que en el litigio en cuestión no existe fecha crítica, o que ni siquiera se haga mención de la misma ${ }^{33}$. En este último caso, la fecha de sometimiento de la controversia ante el tribunal actuará de facto como fecha crítica.

\section{Una reflexión final}

Lamentablemente, las controversias territoriales han sido, son y serán una constante de las relaciones internacionales. Lo importante, sin duda, es arreglarlas de forma pacífica. A este respecto, la Corte Internacional de Justicia a lo largo de sus casi setenta años de existencia ha desempeñado un papel fundamental en su arreglo, siendo precisamente este tipo de contenciosos los que más se suscitan ante ella.

El resultado es un amplio bagaje jurisprudencial a través del cual se ha ido asentando un conjunto de reglas y principios que sirven de guía, no sólo para la propia Corte, sino también a los eventuales arbitrajes que puedan constituirse para resolver alguna de las controversias territoriales aún pendientes. Principios tales como el de la primacía del título jurídico, la subsidiariedad de la posesión efectiva, el de relatividad de la efectividad, o el valor residual de la cartografía cuentan con un amplio respaldo jurisprudencial. Como

\footnotetext{
${ }^{3 \mathrm{I}}$ Asunto de la Controversia territorial y marítima entre Nicaragua y Honduras en el Mar Caribe (CIJ Recueil, 2007, pp.697-698, pa.II7).

${ }^{32}$ Vid. FitZMAurice, G.SiR, «The Law and the Procedure of the International Court of Justice, I95I-4: Points of Substantive Law», BYBIL, I955-56, pp.22-26.

${ }^{33}$ Sí se ha fijado fecha crítica en los siguientes asuntos: Groenlandia oriental (Io julio I93I), Minquiers y Ecrehous (I886 y I888, respectivamente), El Salvador/Honduras (I980), Benín/Níger (i960, coincidiendo la fecha crítica con la del uti possidetis), Pulau Sipadan y Pulau Ligitan (I969), Nicaragua c. Honduras (I977), Pedra Branca, Middle Rocks $y$ South Ledge (I4 febrero I980 y 6 febrero I993, respectivamente),y Nicaragua c. Colombia: I2 junio ig69. Mientras que no se ha hecho uso de la misma en los contenciosos relativos a la Soberanía sobre ciertas parcelas fronterizas, Templo de Preah Vihear, Burkina Faso/Mali (aunque indirectamente la asimila a la del uti possidetis, I960), Libia/Chad, Isla de Kasikili/Sedudu, Qatar c. Bahrein, y Camerún/Nigeria.
} 
también lo tienen algunas reglas procesales como la de la fecha crítica o la de la mejor prueba. Por no hablar de los importantes desarrollos producidos en el derecho territorial.

Si importante son estas reglas y principios para los jueces y los iusinternacionalistas, más aún lo son para los Estados implicados en una disputa territorial; pues el previo conocimiento de cuáles son las pautas de solución puede constituir una ayuda inestimable a la hora de presentar sus alegaciones y defender sus intereses ante una instancia internacional. 